\title{
Evaluating the relationship between the requirements of teleworking government establishments with the success of teleworking program in Fars province
}

\author{
Foroogh kamyar ${ }^{1}$, Parviz saketi² \\ ${ }^{1}$ Master of Educational Management,Shiraz Branch, Islamic Azad University, Shiraz,Iran \\ Icdlteacher7@gmail.com
}

${ }^{2}$ Doctor Educational Management,Shiraz Branch, State University, Shiraz,Iran

ppparviz@gmail.com

\begin{abstract}
Methodology / Approach: To identify the relationship between parameters of teleworking and its success rate in the governmental agencies of Fars province. Population and Statistical Sample: All the inspectors in the Bureau of Labor and Social Affairs, that include 21 members from the operator information "118", 50 members from the Fars province Telecommunications ministry, with and a total population of teleworkers of $n=71$ were studied in this research, of which 20 inspectors from the of Fars province and 30 operators information office enquiries "118", therefore a total n=50 completed the Teleworking questionnaires. Purpose of this study: To evaluate the relationship between the dependent variable (success teleworking) and 5 independent variables (1.rules and regulations 2. the support of Top management 3. perceived benefits of teleworking 4. Trust 5. Culture). Analysis: Descriptive and inferential statistics were carried out, including Pearson correlation, linear regression and multistage regression. Conclusion: The results of this study clearly show that compliance with the Constraints and limitations had a direct and significant impact on the success of teleworking. An interesting point, in this study, is that the simultaneous linear regression model results indicate a significant relationship at relatively high level (69\%) between requirements of each of the variables with the success of telework. The results of multiple regression indicate that with regards to the simultaneous effects of the variables consisting of 1.Top management supported 2. Trust 3, Rules and Regulations, 4.Culture, there was a significant correlation with successful teleworking. However, the perceived benefits variable was not significant in the model, and as such the simultaneous effect the cycle was removed. In the information age, with the fast development of systems technologies and telecommunications, a telework program is not just a likely option but a clever and strategic business decision.
\end{abstract}




\section{Introduction}

$\mathrm{T}$ eleworking is one of the methods that allows for accelerated product development in information technology and communication. This comes as countries are moving from a society based on industry to an information based society. The move, revolutionary at the time, has created new working conditions for individuals and in terms of the place and nature of work (Aqajani, 2011). But in the world today, following the use of information and communication technologies and organizational work carried out, the use of Teleworking has allowed this technology in the world to grow (Ansari et al., 1389). The employers' ability to maintain or strengthen its status in global competition for employment is always considering new and possibly cheaper alternatives. In the age information, with the rapid progresses in technology and telecommunication systems, there is a continuous need develop programs that are not only practicable, but also hold a competitive edge in today's open world economy. The adverse effects of increased urban travel, morning and evening traffic and congestion, increased commuting costs, and urban pollution have all effected people and wasted vast amounts of time for people to get to work. Also, energy loss, developing a new relationship between the employee and manager, and the presence of women which include $60 \%$ of those admitted for examination and culture for educating children places great importance on technology and the role of women at home. Therefore, through technology and teleworking it can be understood that part-time work and working from home can be helpful.

\section{The purpose of this article:}

To evaluate the relationship between the dependent variable (teleworking success) and 5 independent variables. Also, to evaluate whether there is an ability to communicate between employees and managers, positive comments about the plan to work out successful understanding of the spread of teleworking.
Finally, to create an active consciously planned environment through human resources associated with the project. This will allow the finding of an association between the requirements of teleworking and successful planning.

\section{The structure of this paper}

The theory and research resources include: 1 . Organization and management, administrative and employment laws and regulation of timework, ICT and timework; 2. technology experts and residents including, ICT, employment in the Bureau of Labor and Social Affairs, Telecommunications department in Fars province 118 (Data Center) and Fars province (data collection questionnaire ); 3-methodology (in terms of objectives: using descriptive statistics and analytical approach: comparative and analytical); 4 . The objective: To find relationships and success factors restricted to timework; 5.grouping parameters: the requirements: (law and regulations, Perceived benefits, top management supported, Trust, culture) in the field of readiness to accept the job.

\section{Research hypotheses:}

Main Hypothesis 1: There is a positive relationship between successfully teleworking and requirements of teleworking.

Sub-hypotheses1- 1: There is a positive relationship between successfully teleworking and the rules and regulations.

Sub-hypotheses1 -2: There is a positive relationship between successful teleworking and regulation top management support.

Subhypotheses 1-3: There is a positive relationship between successful teleworking and regulation perceived benefits.

Subhypotheses 1-4: There is a positive relationship between successfully teleworking and building up mutual trust.

Subhypotheses 1-5: There is a positive relationship between successfully teleworking and culture of the community. 
Subhypotheses1-6: There is a significant relationship among the five variables (1. Support of top management 2 . The perceived benefits of teleworking 3. Legislation encouraging and supporting teleworking, 4 . Mutual trust and 5 . Culture) and the success of the program and teleworking.

\section{Theoretical Foundations Research}

Definition: The International Association defined teleworking a form of work where people are flexible in terms of time, part-time or full-time, and location i.e. at home, remote offices or in the form of a tour at different centers (to perform tasks and duties to engaged) (Smith John, 2002).

A) The critical factors (requirements): Critical success factors are those that must provide for the success of the business. These include the factors that have limited the success of the system are vital if the system wants to survive. In other words, the underlying success factor is to do its best to be done (Rezaeian, 1987). Teleworking factors include: (1).The Supportive rules (2).Benefits from teleworking (3). Support of top management (4). Trust of managers (5).Culture

The Supportive rules: To lay and improve the laws in order to facilitate teleworking, expand the public interest, and to control and change the direction of a society. In teleworking special state legislation should facilitate all factors affecting this sector in a timely manner, and to attract people and organizations to move it from some of these laws. It should be noted that in drafting their contracts, there should be reliability and flexibility for people. (Sam Khani \& Begay, 2011) Benefits of teleworking: Teleworking has benefits for staff, customers, the environment and society (Crandall and Gao,2005). Organizational benefits of teleworking includes an increase in efficiency, therefore reduce operating costs and the ability to virtually adapt to the new hire (Schweitzer, 2006). By studying the employers and employees use of teleworkers organizations will be more able to support, recruit and retain staff (staff scat, 2011). When personal flexibility of teleworking is considered to be very satisfactory, this leads to increased job satisfaction and stability, thus reduces the losses. It allows the possibility of recruiting an expert from anywhere in the world as well as the possibility of recruiting the best talent available. (Haddadi Harandi, 2013). The key Question in the management of teleworkingin in the organization is to identify the factors that affect the performance of employees. If teleworking is effectively implemented the benefits of teleworking is that most challenges and problems are reduced (Gholipour, 2011).

Support of Top management: Teleworking shows a change in the traditional framework of teleworking, however success depends on the ability of management to make this transition. A lot of literature is available on the support of senior management. These have emphasized that with comprehensive training and reliability, and technical solutions to be followed as one of the success factors of teleworking (Monroe, 2006) The Managerial role for the success of teleworking should develop from a host to a trainer or facilitator. This will allow the monitoring of the behavior of teleworkers as the manager must monitor the output.

Trust: Why do managers not trust working awayers?

Common concerns of employees include: the education and development of personal relationships, communication among dispersed workers and evaluating the differences and enduring commitment to the team (Vega 2001). Working awayers, i.e. the employees do not find new work in general and with the busy work load, they do not pay attention to others. This may allow managers and employees to lose control over taxation and legal issues which the employees are often not concerned about (Jalali, 2010). The employers empowering of the personnel raise their confidence and allow them to be in self-control. A significant portion of the company's successful Teleworking Air Touch was dedicated to empowering employees to build relationships based on trust between managers and employees (Tabatabaei,2007).

Culture: The meaning of culture is to " includes all of the intellectual and material aspects of society" (Sadeqpour1985, Yazdi1987). According to the general policies of the administrative system communicated by Iran's supreme leader, on the principle of articles one, twenty, twenty four and twenty six, and according to culture it is important to emphasize the institutionalization of organizational culture based on Islamic 
values. This will allow the extension of administrative and social responsibilities, use of cultural facilities and the continuous improvement of the administrative system to grow (Department of President of the Assembly May 2010). As a result, "teleworkingis a phenomenon in many countries, which was conducted in Finland, for example, strengthens families and reduces divorce. As a result, the implementation and application of teleworking can therefore reduce the presence of an increase in divorced women in the family. Television in the implementation of teleworking culture, thus should not be used by women who stay at home for teleworking (News site teleworking News, 2013).

\section{Literature Review:}

Literature in Iran: Background research on teleworking in the country has been undertaken by Hossein-Zadeh,Siamak (2013). The results demonstrate that despite the existence of problems with teleworking in Iran it also has advantages. Disadvantages include the lack of skills, lack of experience among staff, resistance to change, organizational culture, lack of supportive policies and lack of government attention to teleworking. Other shortcomings are the absence of appropriate legislation, lack of attention to the development of information technology and infrastructure development in the country, lack of adequate security to exchange information and documents related work, the official attitude toward the conservative approach, the lack of information technology skills and the concern of some social problems. On the other hand, teleworking in Iran has many advantages. These include valueadded to businesses, solving the problem of staff absenteeism, reduced consumption of energy and resources, improve the employment and retention of personnel, space reduction and cost reduction, equality among individuals and organizations. Tahavori (2012) concluded that teleworking achieved in the National Library and Archives of the Islamic Republic of Iran appears to show relative success of these procedures in some parts of the organization, in particular the office of processing and organizing. However, the efficiency of its accuracy, especially the evaluation of the efficiency of these procedures requires further research.

Online News (2010) observed that constraints of administrative reform, electronic matters that for started for years with the issue of culture and education, including its methods of telework. For teleworking, infrastructure, managers and reception staff believes is required. A small part of the government on the need to reduce $5 \%$ of people who have reached the $10 \%$ reduction. Medooz (2007) showed that through teleworking research, strong IT support was needed. This included adequate bandwidth and application tools such as e-mail, voice mail, file sharing, screen sharing, instant messaging, video conferencing, data encryption and other capabilities that are mandatory for successful teleworking. Such a system can be expensive, but the benefits are great.

Minh Huu Pham (2010) showed that in New Zealand the lack of support from senior management limits the success of telework in business. He suggested that managers should pay more attention to the support of senior management; workforce and issues of cultural change for a successful telework program.

Lister (2010), discussed that the benefits of teleworking implementation by examining 250 cases of books, articles and documents related to telework and also conducted interviews with many of the employers involved in public and private institutions. His interests in three of the benefits of telecommuting included employers, employees and the community. A design of a calculation of the breakdown of results by Telework Research Network was published. According to this calculation, since 2008, each year more than 645 billion dollars worth of projects have been earned through the benefit of telecommuting in America. 


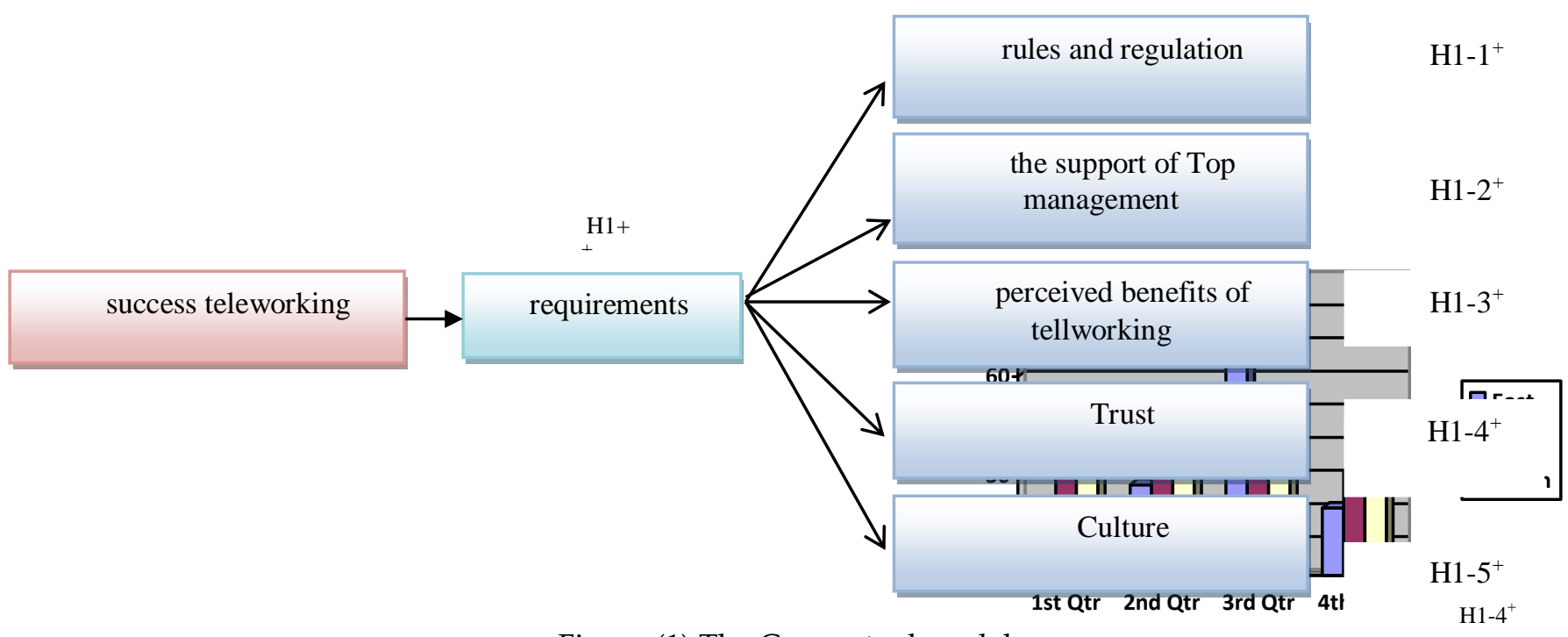

Figure (1) The Conceptual model

\section{Research method:}

Methods: A descriptive of the survey. The population of 21Social Affairs inspectors from the city of Shiraz, 50 participants from the Fars province operator information center (118). 20 Participants from the inspectors Social Affairs from Fars province, sample of 30 participants from the city Shiraz operator information center (118)

Sampling Method: Random sampling was applied. Data Collection Method: A Questionnaire was designed research the "Relationship between the level of readiness of government agencies in the province of Fars successful telework program". Content validity was undertaken by Dr. Saketi and colleagues on 15 participants. The reliability of the questionnaire is equal to $85 \%$ has been estimated by Cranach's alpha. Statistical analysis: Descriptive statistics (mean standard deviation, frequency (number) and frequency) and inferential statistics (Pearson correlation coefficient of linear regression and multiple regression)

\section{Data analysis:}

This section consists of two parts: 1) Description of the data and variables 2) The formation of the findings related to the research hypotheses. Analysis of demographic variables shows that the majority of respondents $(62 \%)$ are of the male gender. The nature of the job of social inspectors $40 \%$ and Telecom operators (118) make up $60 \%$ of the audience inquired.
In terms of working experience, the proportion to measure this variable between 10 and 15 years experience was taken into account. It is noteworthy that only 1 out of 50 respondents (approximately 2\%) are less than 5 years of work experience. On the other hand, responses showed that most participants that answered the questions had their undergraduate degree.

Research Brief:

The results comply with requirements and significant direct effect on the success of teleworking as can be seen on the ultimate model of Figure 2. The results of the correlation of each of the component requirements (supported by senior management, perceived benefits, selfregulation and Culture) and constraints (economic restrictions, restrictions on work, information technology restrictions, restrictions on labor, the risk of negative advice staff).The results of multiple regression, the effect of both variables in the variable requirements:( 1) the support of Top management (2) perceived benefits of tellworking (3) Trust (4) culture (5) rules

The results of multiple regression, in the simultaneous effect variables requirements 4 variable consist of 1.top management supported 2. Trust, 3. Rules and regulations, 4. Culture. There was a significant correlation with successful teleworking. Also, the perceived benefits variable was not significant in the model, the simultaneous effect cycle was removed. 


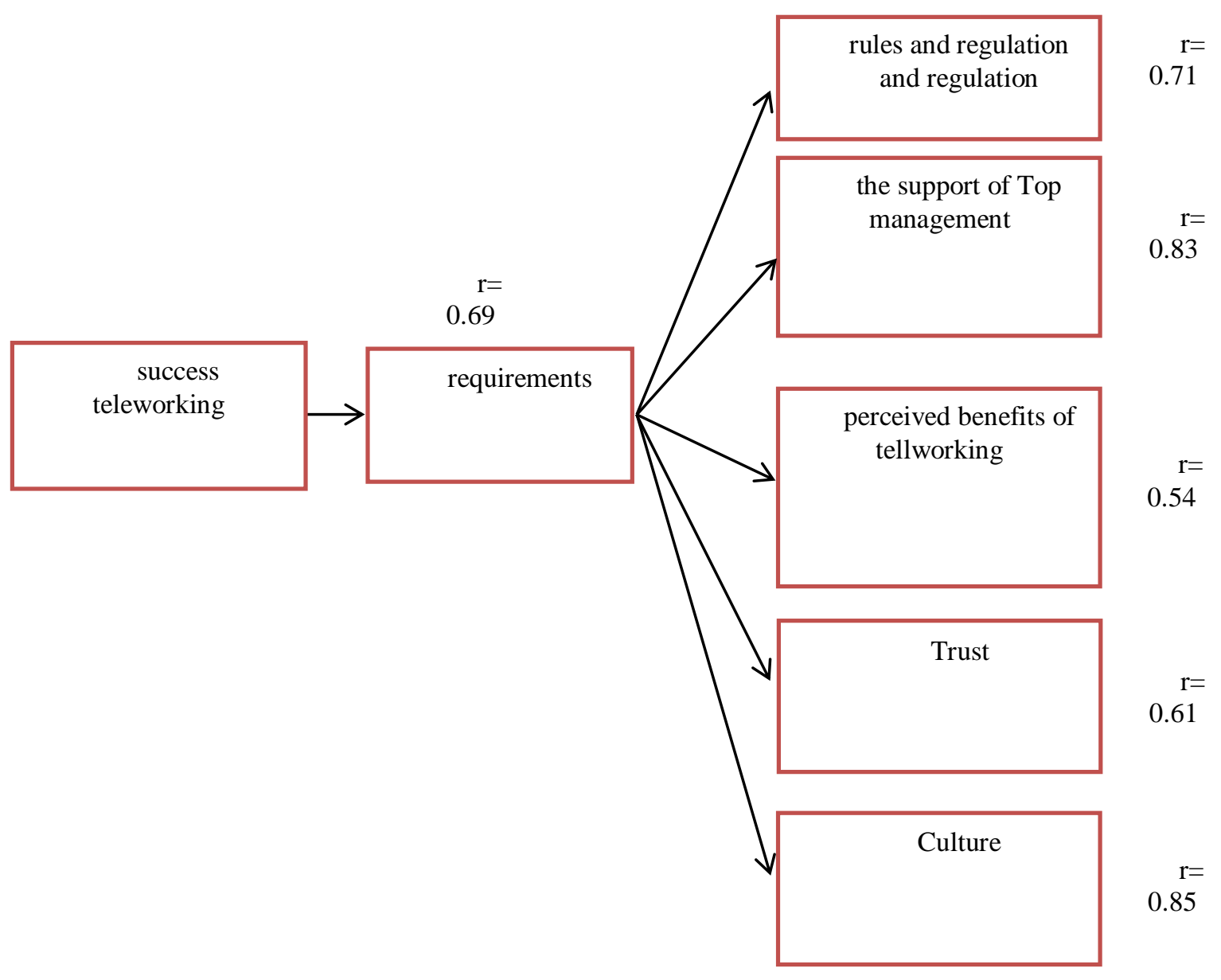

Figure (2) The ultimate model

Table (1) : Results of regression, correlation requirements with the success of telework The results of the regression analysis on the research variables

\begin{tabular}{|c|c|c|c|c|c|c|}
\hline \multirow{2}{*}{$\begin{array}{l}\text { Criterion } \\
\text { Variable }\end{array}$} & $\begin{array}{c}\text { Index } \\
\text { Statistics }\end{array}$ & \multirow[b]{2}{*}{$\begin{array}{c}\text { R Square } \\
\text { RS }\end{array}$} & \multirow[b]{2}{*}{$\begin{array}{c}\text { F Ratio } \\
\text { Possibility( P) }\end{array}$} & \multirow[b]{2}{*}{ Beta } & \multicolumn{2}{|c|}{ Regression coefficients } \\
\hline & $\begin{array}{l}\text { Predictor } \\
\text { Variables }\end{array}$ & & & & $\mathrm{t}$ & $\begin{array}{c}\text { Significance } \\
\text { Level }\end{array}$ \\
\hline \multirow{6}{*}{ 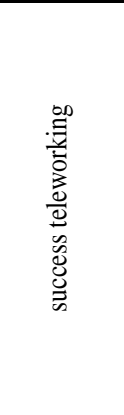 } & requirements & $0 / 48$ & $\begin{array}{c}\mathrm{F}=110 \\
\mathrm{p}<0 / 001\end{array}$ & $0 / 701$ & 11.25 & $\mathrm{p}<0 / 05$ \\
\hline & $\begin{array}{l}\text { rules and } \\
\text { regulation }\end{array}$ & $0 / 50$ & $\begin{array}{c}\mathrm{F}=55 \\
\mathrm{p}<0 / 001\end{array}$ & $0 / 724$ & 12.46 & $\mathrm{p}<0 / 05$ \\
\hline & $\begin{array}{c}\text { the support of Top } \\
\text { management }\end{array}$ & $0 / 69$ & $\begin{array}{c}\mathrm{F}=110 \\
p<0 / 001\end{array}$ & $0 / 851$ & 14.02 & $\mathrm{p}<0 / 05$ \\
\hline & Trust & $0 / 37$ & $\begin{array}{c}\mathrm{F}=84 \\
\mathrm{p}<0 / 001\end{array}$ & $0 / 614$ & 9.39 & $\mathrm{p}<0 / 05$ \\
\hline & $\begin{array}{c}\text { perceived benefits of } \\
\text { tellworking }\end{array}$ & $0 / 29$ & $\begin{array}{l}\mathrm{F}=110 \\
\mathrm{p}<0 / 001\end{array}$ & $0 / 546$ & 8.15 & $\mathrm{p}<0 / 05$ \\
\hline & Culture & $0 / 72$ & $\begin{array}{c}\mathrm{F}=64 \\
\mathrm{p}<0 / 001\end{array}$ & $0 / 865$ & 14.68 & $\mathrm{p}<0 / 05$ \\
\hline
\end{tabular}


Table (2):the results of correlation coefficient, connection requirements to successfully teleworking The results of the regression analysis on the variables

\begin{tabular}{|c|c|c|c|c|}
\hline \multirow[b]{2}{*}{$\begin{array}{c}\text { Criterion } \\
\text { Variable }\end{array}$} & $\begin{array}{c}\text { Index } \\
\text { Statistics } \\
\end{array}$ & \multirow[b]{2}{*}{ (r) } & \multirow{2}{*}{$\begin{array}{c}\text { Significano } \\
\mathrm{e} \\
\text { Level(p) }\end{array}$} & \multirow{2}{*}{ Frequency } \\
\hline & $\begin{array}{l}\text { Predictor } \\
\text { Variables }\end{array}$ & & & \\
\hline \multirow{6}{*}{ 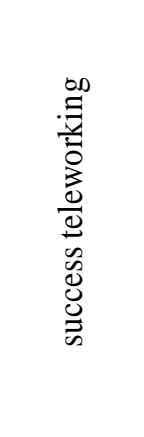 } & requirements & 0.69 & 0.001 & \multirow{6}{*}{50} \\
\hline & $\begin{array}{l}\text { rules and } \\
\text { regulation }\end{array}$ & 0.71 & 0.001 & \\
\hline & $\begin{array}{l}\text { the support of } \\
\text { Top management }\end{array}$ & 0.83 & 0.001 & \\
\hline & Trust & 0.61 & 0.001 & \\
\hline & $\begin{array}{l}\text { perceived benefits of } \\
\text { tellworking }\end{array}$ & 0.54 & 0.001 & \\
\hline & Culture & 0.85 & 0.001 & \\
\hline
\end{tabular}

You can see the effect of each independent variable on the dependent variable (success teleworking) in Table 1.

You can see the results of the correlation coefficient (the relationship between the requirements to successfully teleworking) in Table 2. Removed is just one variable (the benefits teleworking) in the model of interaction requirements in Table 3.

Table (3) multiple correlation coefficients of the variables teleworking requirements to the success of teleworking model of simultaneous effect

\begin{tabular}{|c|c|c|c|c|c|c|c|c|}
\hline \multirow{2}{*}{$\begin{array}{l}\text { Criterion } \\
\text { Variable }\end{array}$} & \multirow{2}{*}{$\begin{array}{c}\begin{array}{c}\text { Index } \\
\text { Statistics }\end{array} \\
\text { Predictor } \\
\text { Variables }\end{array}$} & \multirow{2}{*}{$\begin{array}{c}\text { Multiple } \\
\text { Correlation } \\
\text { MR }\end{array}$} & \multirow{2}{*}{$\begin{array}{c}\text { R Square } \\
\text { RS }\end{array}$} & \multirow{2}{*}{$\begin{array}{c}\text { F Ratio } \\
\text { Possibility } \\
\text { ( P) }\end{array}$} & \multicolumn{4}{|c|}{ Regression coefficients (B) } \\
\hline & & & & & 1 & 2 & 3 & 4 \\
\hline \multirow{4}{*}{ 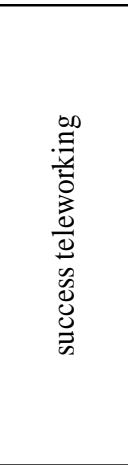 } & Culture & 0.748 & 0.751 & $\begin{array}{c}\mathrm{F}=64 \\
\mathrm{p}<0 / 001\end{array}$ & $\begin{array}{l}(\beta)=0 / 865 \\
t=14.68 \\
p<0 / 001\end{array}$ & & & \\
\hline & $\begin{array}{l}\text { the } \\
\text { support }\end{array}$ & 0.826 & 0.764 & $\begin{array}{c}\mathrm{F}=60 \\
\mathrm{p}<0 / 001\end{array}$ & $\begin{array}{l}(\beta)=.722 \\
t=10.57 \\
p<0 / 001\end{array}$ & $\begin{array}{l}(\beta)=.654 \\
t=9.57 \\
p<0 / 001\end{array}$ & & \\
\hline & The rules & 0.866 & 0.811 & $\begin{array}{c}\mathrm{F}=53 \\
\mathrm{p}<0 / 001\end{array}$ & $\begin{array}{l}(\beta)=.546 \\
t=7.65 \\
p<0 / 001\end{array}$ & $\begin{array}{l}(\beta)=.624 \\
t=6.25 \\
p<0 / 001\end{array}$ & $\begin{array}{l}(\beta)=.546 \\
t=4.49 \\
p<0 / 001\end{array}$ & \\
\hline & Trust & 0.650 & 0.658 & $\begin{array}{c}\mathrm{F}=49 \\
\mathrm{p}<0 / 001\end{array}$ & $\begin{array}{l}(\beta)=.402 \\
t=6.54 \\
p<0 / 001\end{array}$ & $\begin{array}{l}(\beta)=.301 \\
t=557 \\
p<0 / 001\end{array}$ & $\begin{array}{l}(\beta)=.268 \\
t=4.56 \\
p<0 / 001\end{array}$ & $\begin{array}{c}(\beta)=.127 \\
t=2.87 \\
p<0 / 001\end{array}$ \\
\hline
\end{tabular}

\section{Conclusions:}

A.The results of this study clearly show that there was significant compliance with the requirements and a direct effect on the success of teleworking. An interesting point, in this study, is that the simultaneous linear regression model results indicate a significant relationship at relatively high level (69\%) between requirements of each of the variables is the success of telework.

$B$. The results of multiple regression, in the simultaneous effect variables requirements 4 variables consisting of 1.top management supported 2. Trust 3. Rules and Regulations 4. Culture. There was a significant correlation with successful teleworking. Also, the perceived 
benefits variable was not significant in the model, the simultaneous effect the cycle was therefore removed, In the information age, with the fast development of systems technologies and telecommunications, a telework program, is not just a likely option but a clever and strategic business decision.

\section{Suggestion:}

Senior managers, taking into consideration the benefits of telework, utilizing their support and motivational skills, may provide the appropriate conditions for the employees to successfully telework. This will allow the protection of the interests of the organization and the realization of the objectives of the projects.

Create the incentives, support and facilitate the implementation of teleworking in laws and regulations, including employment.

- Create a climate of mutual trust through communication between employees, managers and executives is very important to successful teleworking.

Promoting teleworking as a determining factor plays an

important role in the adoption of teleworking. It should be done through media, expert and specialist conducted seminars.

\section{Limitations:}

Questionnaire: This perception is not fully adapted to reality. 2. The extension of the limitation of this study in the Department of Labour and Social Affairs manages communications (data 118) only in Shiraz. Therefore, in generalizing the findings to other government agencies, this should be considered with caution.

\section{References:}

1.Aghajani, H., (2011), factors affecting the adoption of teleworking by female employees at the Department of Social Affairs, Science degree in guidance and updates Zareie A. Mani, Tehran, Tehran University School of Entrepreneurship.
2.Crandall, W\& ,.Gao, L. (2005). An update on teleworking: reattitudes and prospects for emerging issues.

3. Gholipour, (2011), Arian and his colleagues analyzed teleworking challenges with an emphasis on legal challenges in Iran, Proceedings of the Conference on teleworking in the administration, challenges and solutions (p. 61-60).

4. Haddadi Harandi, Ali Akbrv et al. (2013), examining the limits of telework implementation approach theoretical limits, the seventh national conference and the first International Conference on Electronic Commerce and Economics, Tehran, Iran Electronic Commerce Association.

5. Haddadi Harandi ; Radfar, R \&Ghaffari, F, (2013), thesis "Study of Constraints and limitations of implementing telework governmental organizations (case study research centers of Road and Urban Development)".

6. Hosseinnezhad. s" Teleworking in Governmental Organizations, Infrastructures, Advantages and Disadvantages of Teleworkingin Iran" Journal of American Science 2013;9(5s)

7.Lister, K. \& Hanrish, T.,(2010), “ Work shifting benefits: The Bottom Line" Telework Research net work/Aerodite, Inc.

8.Meadows, V, (2007),Versatile bureaucracy: A telework case study. Public Manager, p.33-36

9. Minh HuuPham,(2010), An investigation on the constraints to telework implementation in New Zealand businesses.

10.Oly Ndubisi, Nelson, \& Kahraman, Cengiz, (2005), Teleworking adoption decisionmaking processes : Multinational

and Malaysian firms comparison., The Journal of Enterprise Information Management, 18, (2), 150-168.

11. Pérez Pérez, M., Marínez Sánchez, A.M., De Luis Carnicer, M.P, \& Vela Jiménez M.J, (2008), Telework

adoption, change management, and firm performance. Journal of Organizational Change Managemen, 21(1), 7-31. 
12. Sam Khani, S, (2011), "strategies, methods and tools teleworking" Proceedings of the National Conference on teleworking in the civil service, Page 38.

13. Sadeqpour, A., (1391), Masters, identify factors affecting the tax from employee telecommuting in the tax affairs of Tehran ", S.49-57

14. Siha, S. M., \& Monroe, R. W, (2006), Teleworking's past and future: a literature reattitudesand research.

15. Tremblay, D. (2002). Balancing work and family with telework? Organizational issues and challenges for women and managers. Women in Management Review, 17(3/4), 157170

16.Tabatabai, n, (1386), location of teleworking centers. Masters, the guide Mohammad Kermanshah, Tehran, Sharif University of Technology School of Civil Engineering.

17. Tahavori, Z, (2012), Encyclopedia of the point of attitudes of processing and organizing employees telework Office of the National Library of the Islamic Republic of Iran. 